\section{More than just a digital event}

If you have missed the normal round of conferences and other opportunities to talk dental this year, then don't worry: you only have a few weeks more to wait. Henry Schein is excited to announce a brandnew event: Dentology - powered by Henry Schein is an online virtual 3D dental conference, taking place on 29 and 30 January 2021.

This may be your first opportunity in a long while to feel truly connected with like-minded members of your profession, but as you enter the virtual conference hall, complete with multiple virtual stages, you'll be transported into an interactive 3D world that brings digital dentistry to life.

Dentology will be more than just a sensational online event; it will be a new community, created by global leaders in dentistry, who want to share their experience with others who are searching for new solutions, new tools and new ideas.

You will be able to get up close to the three keynote speakers: the world's top-searched dentist on Google, Christian Coachman, founder and CEO of Digital Smile Design; leading UK cosmetic dentist, Dr Simon Chard; and special guest, Randi Zuckerberg, Founder and CEO of Zuckerberg Media and former Director of Marketing at Facebook.

You'll be able to interact with the global faculty of speakers, pop in and out of virtual breakout sessions as many times as you like, visit the 3D exhibition hall (available for participants from EMEA countries with Henry Schein operations) with comprehensive information around intraoral scanners, chairside milling, 3D printers, 3D CBCT, air management, sterilisation, microscopes and lasers, treatment centres as

\section{Your first response}

If you, a staff member or a patient has entered your practice and is later confirmed to have been infected with coronavirus, you need to act fast.

Initial Medical has put together an Infection Containment Kit that is the ideal first response to this situation.

The kit includes everything you need to isolate and contain the infection and meet your duty of care requirements. The Steri-7 products in this kit are also effective against a wide array of pathogens, including coronavirus, norovirus, MRSA, influenza and many more, making it the perfect first line of

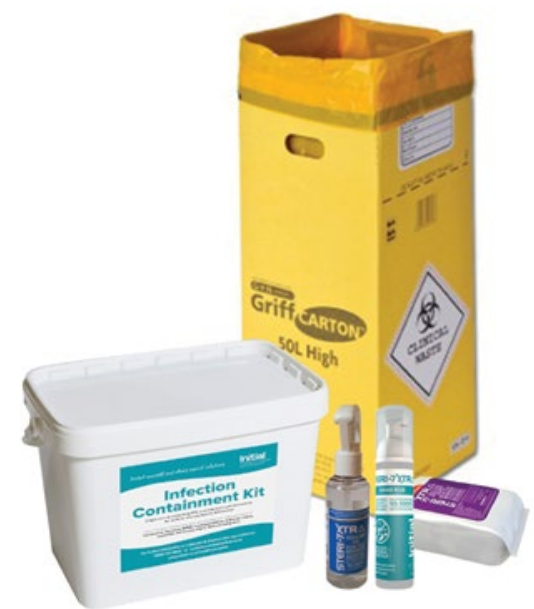
defence against a large variety of infectious illnesses.

It comes with complete step-by-step guidelines on how to use each of the items inside and, once used, the waste will be collected and disposed of responsibly by the Initial Medical team.

Act fast with the help of Initial Medical - contact the team today for more information.

For further information visit www.initial.co.uk/medical or call 08708504045.

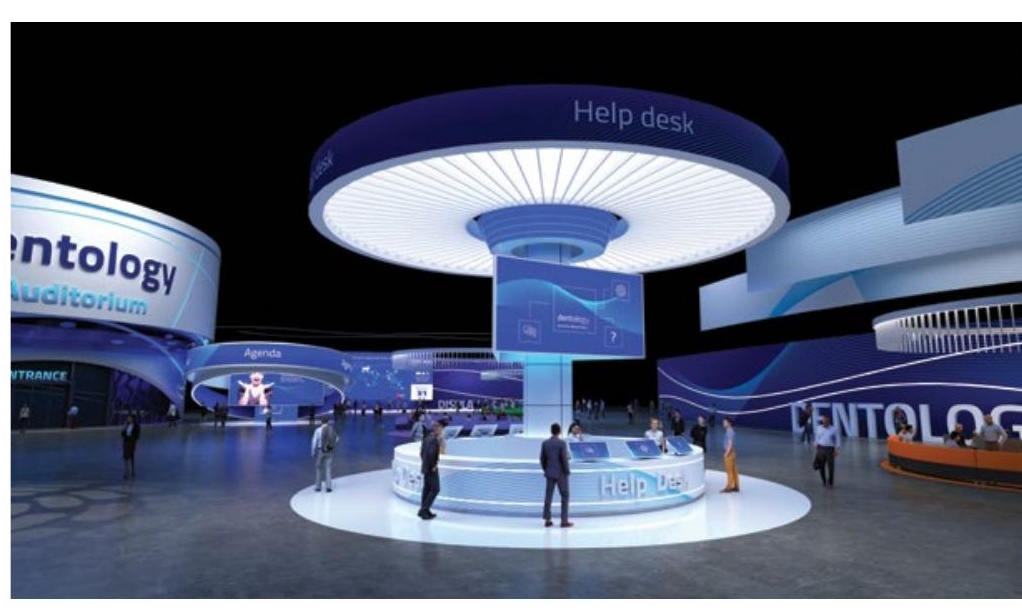

well as digital dentistry related surgical and orthodontic products, and speak with Henry Schein's digital specialist team in real time during the live event.

Almost better than a real conference, there'll be more chances to make the most of the opportunities available, catch up on missed lectures online - plus no passes to lose, maps to decipher or aching feet, as you access everything from the comfort of your own computer.

With the purpose of showcasing, sharing and exploring what the future of dentistry holds, Dentology will be defined by its ability to virtually connect and drive that future forwards.

Save the date: 29-30 January 2021! Register your interest at https:// www.dentology.world/.

\section{Sustainably produced oral hygiene products}

From autumn 2020 onwards, TePe Oral Hygiene Products will be part of the STEPS research programme as an industrial partner. STEPS' vision is a society where plastics are sustainably produced, used and recycled in a circular economy. TePe's commitment is in line with the company's aim to promote sustainable development throughout the value chain.

STEPS, Sustainable Plastics and Transition Pathways, led by Lund University, brings together researchers from various disciplines as well as industrial partners who represent the entire value chain

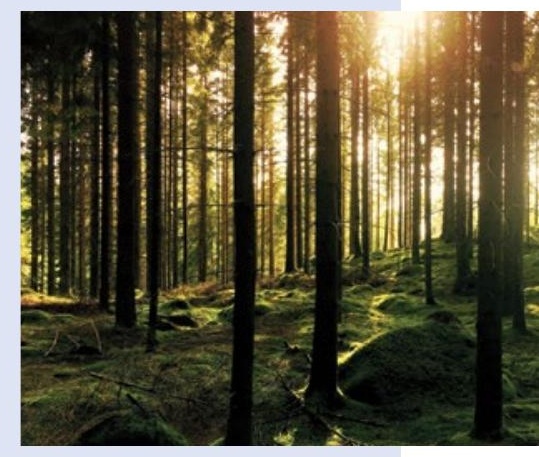
in plastics, from raw materials to finished products. The second phase of the programme, running from 1 September 2020 to 31 December 2024, puts focus on intensifying collaboration between new industrial, regional and research partners to co-develop and evaluate carbon-neutral plastic products for specific target applications. The programme will also identify challenges for transition and suggest potential pathways for circular economy and reduced plastic pollution.

STEPS is funded by Mistra, the Swedish Foundation for Strategic Environmental Research, which supports research of strategic importance for a good living environment and sustainable development. 